Haklay, M., 2002, Public Environmental Information - Understanding Requirements and Patterns of Likely Public Use, Area, 34(1), 17-28

\title{
Public Environmental Information - Understanding requirements and patterns of likely public use
}

Mordechai Haklay

Lecturer in GIS

Department of Geomatic Engineering and Centre for Advanced Spatial Analysis

University College London

Gower Street, London, WC1E 6BT

E-mail: m.haklay@ucl.ac.uk

\section{Summary}

Public access to environmental information received much attention in the last decade. Recent developments promote access to this information through public telecommunication networks. This paper describes a Web-based survey that explored the requirements and needs of likely users of public environmental information systems for London: educated middle-class members of the public, with high interest in environmental issues and computer literacy. The survey demonstrated current information consumption patterns and the reasons to gather and use such information.

\section{Introduction}

The nature, quality and amount of publicly accessible environmental information has been a high profile issue ever since the inception of the modern environmental movement. The well known US milestone of the National Environmental Policy Act (U.S. Congress 1970) - NEPA - entails a number of important environmental information elements, especially with regard to discussion of environmental impact statements and state of the environment reports. The more recent Rio Declaration (UN 1992b) and Agenda 21 (UN 1992a) link information provision to the principle of sustainable development. Principle 10 of the Rio declaration reads:

"Environmental issues are best handled with the participation of all concerned citizens ... each individual shall have appropriate access to information concerning the environment that is held by public authorities, ... and the opportunity to participate in decision-making processes... " (UN 1992b, Principle 10).

Several developments during the 1990 s came specifically to address access to information, and conventions and legislation that promulgate public access to environmental information have been developed and signed. These include European Council Directive 90/313/EEC "Freedom of Access to Information on the Environment" (Hallo 1997) and the Aarhus convention on "Access to Information, Public Participation in Decision Making and Access to Justice in Environmental Matters" (UN/ECE 1998). 
At a declarative level, then, we are moving into a situation where environmental information is tightly related to public participation in decision-making and awareness of environmental matters. In this new 'environmental information age' public telecommunication networks also hold a pivotal role and the Aarhus convention mentioned them explicitly (UN/ECE 1998). Furthermore, the Internet and the World Wide Web (WWW) are perceived as the major media for information delivery in the environmental domain (OECD 2000). Of course, such focus should be seen in the wider context of using Information and Communication Technologies (ICT) for environmental ends (Pickerill 2000, Rogers 1998,Bullard 2000) and for wider public participation in decision-making (Shiffer 1999, Castells 1996).

This paper discusses the results of a Web-based survey, which explores the expressed needs and patterns of use of environmental information. The survey targeted the "likely audience" for Internet-based Public Environmental Information System (PEIS) for London - middle-class members of the public, with a high level of interest in environmental issues and ICT literacy. Although this group is by no means representative of the general population it is important to understand their needs, for two reasons. Firstly, they are likely to be the "early adopters" and users of PEIS, and secondly, they hold the potential to act as information intermediaries who can help in distributing the information to a wider audience ${ }^{1}$.

The paper starts with a background review to support the claim that the likely audience of PEIS will have the profile that was described earlier. The method that was used for the survey is explained in the second section. The third section discusses some of the key findings from the survey. It opens with a profile of the respondents, followed by a review of the substantive findings - especially the use of different personal "identities" when approaching environmental information and the importance of traditional media in providing it. Section five discusses the main lessons from the survey - the need for action supporting information combined with more general "need to know" usage and the role of the Web in providing such information. Finally, conclusions are drawn.

\section{Background}

PEIS is, by its nature, a socio-technical entity which is influenced by the social milieu - such as interest in environmental matters - and technical issues - for example the ability to access the Web or technical design issues. Of the vast array of topics that might influence PEIS use, two are of special significance for the design of a survey, as they have direct influence on the selection of the survey's target audience and the usefulness of the Web for such a survey. These topics are the environmental attitudes of different sectors in society and their levels of access to the Internet. As we shall see, current patterns of Internet use and public attitudes to environmental issues provide sound grounding for the survey.

\footnotetext{
${ }^{1}$ For discussion on the possibility of information intermediation and model for such information distribution see Chapman et al. (1997)
} 


\section{Environmental attitudes}

Since the mid 1970s, many associations have been suggested between environmental awareness and high levels of education, and, thence with middle-class socio-economic status (Such as Inglehart (1977) or Dunlap et al. (2000)). Although it is important to clarify that environmental awareness is not exclusive to this group and many research projects have demonstrated that environmental concerns involve people from all walks of life (Eden 1996, Irwin 1995, Harrison et al. 1996, Burgess et al. 1988), socio-economic status is still regarded as an important factor when environmental awareness and activities are analysed (Hawthorne and Alabaster 1999). Such trends were identified in multiple scales - up to the global one (Diekmann and Franzen 1999).

Examination of UK case studies (Witherspoon 1994, Witherspoon and Martin 1992, Bristow 1996, Hawthorne and Alabaster 1999) reveals that, in general, the population of South-East England shows higher awareness to pollution and global issues when compared to the general population. Witherspoon (1994) reports that the level of educational attainment does not seem to have an impact on awareness of local environmental issues, but does with regard to global environmental issues - a view supported by other studies (Harrison et al. 1996). According to these analyses, the connection between education and environmental awareness is mediated by political awareness, which stimulates interest and a will to act.

Hawthorne and Alabaster's (1999) environmental citizenship model provides more recent support for the connection between income, education and social class and environmental awareness. It has also been found that those with scientific knowledge display above average level of concern towards the general environment and for self and family (Witherspoon 1994).

With respect to access and use of environmental information, the hypothesis that emerges from these studies is that educated members of the middle-classes should be more interested in PEIS and are more likely to use it then other sections of society.

\section{Access to the Internet}

The lack of equality of access to ICT, or the "digital divide" as it has been termed (USDOC/NTIA 1999), is of special concern regarding PEIS. One of the central tenets of sustainable development is the need for a focus on inclusive modes of decision-making. The Aarhus convention makes a clear connection between environmental justice, access to information and the use of public telecommunication networks for information delivery (UN/ECE 1998, OECD 2000). Equity in access to the Internet, therefore, affects its suitability to serve as a medium for PEIS.

The survey reported here was conducted towards the end of 1999, at a time when the estimated percentage of Internet users in the UK was about 21\% of total population (CommerceNet/Nielsen Media 
Research 1999)2. Among them, only 44\% had access to the Internet on a daily basis (or in other words, just $10 \%$ of the total population). Figures from National Statistics in the UK (published July 2000), suggest that $25 \%$ of households have Internet access from home (Bowman 2000). However, only 3\% of those who are in the second lowest income decile groups have access, contrasted with $48 \%$ of those in the uppermost group (Bowman 2000). Analysis of Internet access among London's population (Foley 2000) supports the assumption that usage in the capital is significantly higher than the UK average, in part because of greater numbers of access points (such as Cybercafés, etc.) combined with the socio-economic profile of London's population. This suggests continued validity of Castells' conclusion that “Computer Mediated Communication (CMC) is not a general mode of communication and will not be so in the foreseeable future ... it will exclude for a long time the large majority of humankind" (Castells 1996 p. 358).

\section{Survey Methodology}

\section{Questionnaire design}

For the purpose of elucidating the opinions and perspectives of potential users of PEIS, a Web-based survey was design. During its development, a pilot study was conducted which identified different potential user groups (education, media etc.) of PEIS, as well as a list of topics that might be of interest to them with respect to a London-based, urban PEIS. This was augmented with the US Environment Protection Agency (EPA) report that summarised a public consultation process about needs of environmental information (Princeton Economic Research Inc. 1998).

Based on these sources, a questionnaire was designed as a set of three forms, in which the respondent was faced with a mixture of closed questions and open ones, designed to provide a range of quantitative and qualitative responses. The questionnaire focused on the following issues:

- Types of information which are of interest - like traffic, air pollution, or noise, the importance of this information and the frequency of updates.

- Opinions about the content and presentation of environmental information systems, current use of information sources and perceived advantages and disadvantages of Internet based PEIS.

- Demography - gender, age, occupation, generalised home address (district level postcode) and Internet usage patterns.

\footnotetext{
2 The same source estimates that by mid 2001 around $46 \%$ of total population are connected (CommerceNet/Nielsen Media Research 2001). However, this is an high-end estimation and other sources offer more modest figures.
} 
The language and context of the questionnaire addressed respondents as citizens with interest in environmental issues, such as "please indicate your personal interest in the environmental issues listed below" or "which of the issues is most important to you".

Next, an Internet address (www.leo.ucl.ac.uk) was established and a skeleton Website was developed with the title "London Environment Online" (LEO). The Website provided respondents with information about potential advantages of access to environmental information, and links to existing PEISs including governmental sites (the Environment Agency and the Department of Environment), a Non Governmental Organisation - NGO (Friends of the Earth) and systems in other countries (Germany and the US). The questionnaire itself was set up as an interactive set of forms which are answered online. Finally, the questionnaire was evaluated by about 40 targeted reviewers, including environmental professionals and academics with interest in environmental studies.

\section{Recruitment}

As it is likely that people who work within a university and their social contacts will match the profile that was developed earlier, it was deemed appropriate to launch the survey by an e-mail shot to university workers. The inherent bias of access to the Internet and the recruiting technique is, actually, advantageous for the purpose of the survey - the interaction with a Web-based survey is self-evidentiary to computer literacy, and the socio-economic and educational attainment of university workers (including academics and postgraduate students) is useful in the survey's context.

In mid May 1999, an e-mail message was sent to a list which includes all the academic and managerial staff, as well as postgraduate students of University College London (UCL). The message asked explicitly to forward the message to other interested parties in order to "snowball" the survey. To extend outreach still further, a leaflet was distributed at a general environmental fair, held in South London, and sent to public libraries in London with Internet access.

\section{Findings}

The Website ran for about six months. Based on analysis of unique computer Internet Protocol (IP) addresses and time stamps it is estimated that, in total, just over 1,100 visitors accessed the Website and about 385 answered the questionnaire. The qualitative sections of the survey proved successful and yielded about 40,000 words of text. This information provides a rich contextual picture of respondents' views and opinions. At the same time, the abilities of the Web-server software to log every interaction and the information that the respondents submitted provided a rich source for quantitative analysis. Together, the two streams enabled a depiction of the survey's audience. This depiction, in turn, matched the profile that was suggested earlier, and can be regarded as representative of a likely PEIS user group. 


\section{Respondents' profile}

The Web-server access log file provides rich information that can help in constructing the respondents' context. The access $\log$ is a list of all the requests for individual files from the Website. The analysis of the access $\log$ provides the following hints: It is most likely that the survey was answered by respondents who lived or worked in London, during the first half of the working day in the second half of May 1999. Most respondents $(88 \%)$ followed the hyperlinks to the survey directly from the front page or after accessing the "about" page. The next phase took about 15-30 minutes in which the questionnaire was answered. In about half of the cases, the respondents provided contact details after completing the survey - an indicator of the interest in the development of the system (for a detailed analysis of the access log see Haklay 2000). According to their postcodes, there are more responses from inner London, and fewer from the neighbouring counties. The respondents to the survey were not concentrated in any specific area, and by and large were distributed across the Greater London area.

As for gender and age distribution, $45.8 \%$ of respondents identified themselves as females, $50 \%$ as males, and $4.2 \%$ preferred not to answer. The distribution across gender and age groups is displayed in Table 1 .

\begin{tabular}{lrrrr}
\hline Age group & N/A & \multicolumn{1}{l}{ F } & \multicolumn{1}{l}{ Total } \\
\hline N/A & $1.1 \%$ & $0.3 \%$ & $0.3 \%$ & $1.7 \%$ \\
$14-24$ & $1.1 \%$ & $10.4 \%$ & $7.3 \%$ & $18.8 \%$ \\
$25-34$ & $1.1 \%$ & $21.3 \%$ & $23.5 \%$ & $45.9 \%$ \\
$35-44$ & $0.3 \%$ & $6.7 \%$ & $12.3 \%$ & $19.3 \%$ \\
$45-54$ & $0.0 \%$ & $5.9 \%$ & $3.6 \%$ & $9.5 \%$ \\
$55-64$ & $0.6 \%$ & $0.8 \%$ & $2.8 \%$ & $4.2 \%$ \\
$65+$ & $0.0 \%$ & $0.3 \%$ & $0.3 \%$ & $0.6 \%$ \\
Total & $4.2 \%$ & $45.7 \%$ & $50.1 \%$ & $100.0 \%$ \\
\hline
\end{tabular}

Table 1 - Age groups and gender

As expected from the original recruiting technique, the stated occupations of the respondents were concentrated in several groups:

- University/research occupations (lecturers, researchers, scientists);

- Professional occupations (IT professionals, administrators, consultants); and

- Students (postgraduate/research students)

However, it is important to note that over $35 \%$ of responses originate from non-academic audience.

About fifth of the respondents identified themselves as active in Environmental NGOs, compared with about $6 \%$ in the overall population (Witherspoon 1994).

Finally, the level of Internet access and computer literacy among the survey's respondents was particularly high. A very high percent (just over 69\%) of the respondents have access to the Internet on a daily basis. 
This high-level of connected-ness is reinforced by the pattern of places from which the access originates. Almost $30 \%$ of respondents have access both at home and work or university.

\section{Environmental issues}

As explained, the first section of the questionnaire focused on interest in environmental issues, reasons for this interest, frequency of update of the data in the system, and an option to mention issues that are missing from the list in the questionnaire.

Using a weighted index based on level of interest ${ }^{3}$, the list of environmental issues that was presented to the respondents was organised according to "interest ranking" in the following order: Public Transport (2.69), Air Quality (2.57), Traffic (2.39), Water Quality (2.29), Recycling / Waste management (2.21), Environmental Health Risks (2.11), Noise Pollution (1.97), Biodiversity / Ecology (1.92), Land Use / Planning (1.83), Contaminated Land (1.82), Environmental Regulations (1.60) and, finally, Environmental Campaigns (1.55). As for the rate of updates, a similar picture emerges.

Most of the respondents (87\%) gave detailed answers for the reasons behind their interests and expressed various viewpoints. The answers were articulated and the text analysis gleaned several 'identities' that were used to construct the viewpoints.

These positions or perspectives can be broadly divided into four groups. The groups are:

1. Individuals who care for themselves and their family;

2. Commuters who need to commute in London on a daily basis (be it by public transport, car or bicycle);

3. Members of the public who want to be active in their community; and,

4. Professionals who use the information as part of their job.

The individual's perspectives focus on issues of care - concerns about health and quality of life. These concerns are on a personal level and for one's family. Some respondents mention a direct connection to health while others express more general concerns:

\footnotetext{
3 The interest index, and the ranking that is based upon it, were calculated as a weighted index in the form: Interest index $=($ (“very interested" responses $) * 3+$ (“interested" responses $) * 2+$ ("possibly interested" responses) *1) / N (Total responses). "No interest" responses received the value 0 . The index can be seen as a measurement of general interest in a topic and takes a value between 0 and 3 , where 0 denotes "no interest" and 3 "total interest".
} 
"Firstly because of how these issues affect me/my family. Health and wellbeing of all is at risk..."

The commuter's perspective deals with the daily chore of travel through London's busy traffic. Inside this perspective three viewpoints can be identified. Those include a public transport user:

"Being a frequent user of public transport and a pedestrian, I am upset by the quantity of traffic in our capital. This affects us all, through noise, air pollution, time it takes to travel and aesthetics. I do believe that if public transport was improved/ cheaper / quicker then the number of people who feel the need to use private vehicles would drop..."

Other positions were those of keen cyclists and private car commuters. Interestingly, as the car is denounced as a major cause for environmental problems, these views are expressed in a somewhat apologetic manner:

“...I do drive but would prefer a decent public transport scheme."

The third identity group is as a community-oriented member of the public. They focus on issues of activity and involvement in the political process. Respondents mention the connection between environmental interests and life in London. A more explicit citizenship identity is expressed when some political action can be taken. Issues of planning, recycling or environmental campaigns directly connect to a sense of political action.

The fourth and final identity is the professional stance. This stance deals with the information that is needed to carry out the daily professional tasks effectively and efficiently.

These identities are not expressed in solitude. Many answers combined several identities and mixed them. It seems that respondents connect different issues to various aspects of their daily life. However, it is impossible to identify an unambiguous connection between a specific topic and a certain identity (i.e. it is inaccurate to claim that air pollution is just a health concern). The respondents express views that demonstrate various issues into an holistic account of the environment (though in the following example the respondent finds the culprit):

"I *HATE* the level of car use in London; it poisons the air, creates interminable noise and doesn't actually solve transport problems effectively. So "traffic" as it is the source of the others!"

About third of the respondents noted that there are some issues that are missing from the list (while few others noted "None that I can think of"). Broadly speaking, these issues can be grouped into 14 headings. Table 2 lists the topics and the number of respondents who mentioned them in their responses. Each issue was identified by relatively small number of respondents and in many cases by only one or two. However, the range of topics that this table represents is important for gleaning respondents' personal definition of useful environmental information. 


\begin{tabular}{|c|c|c|}
\hline Topic & Issues & Count \\
\hline Transport & $\begin{array}{l}\text { Cycling \& cycle paths, alternative transport means (including cycling and } \\
\text { waterways), heavy traffic (lorries and trucks), parked cars and problems } \\
\text { related to them, private car washing, regulations discouraging road traffic, } \\
\text { transport infrastructure / road building, air traffic }\end{array}$ & 24 \\
\hline $\begin{array}{l}\text { Built environment, } \\
\text { Planning }\end{array}$ & $\begin{array}{l}\text { Urban renewal, Eco-design of building (energy consumption, materials etc.), } \\
\text { environmental building regulations, housing, pedestrianisation, population } \\
\text { density pressures and human load on the environment, } \\
\text { strategic environmental planning and practice for London, } \\
\text { work environment (office, stress etc.), urban design for safety and } \\
\text { accessibility, historic environment (listed buildings, archaeology etc.) }\end{array}$ & 19 \\
\hline $\begin{array}{l}\text { Food and food } \\
\text { production }\end{array}$ & $\begin{array}{l}\text { Genetically Modified Organisms (GMO technology), } \\
\text { organic food ("pure food"), agriculture practice: intensive farming, livestock } \\
\text { practice }\end{array}$ & 18 \\
\hline $\begin{array}{l}\text { Green Spaces, parks, } \\
\text { ecological habitats }\end{array}$ & $\begin{array}{l}\text { Green spaces (parks, recreational areas), } \\
\text { the relation between built environment and natural conservation, } \\
\text { protection of greenfield sites under threat, } \\
\text { conservation of wild life and natural habitat }\end{array}$ & 16 \\
\hline "Urban" waste & $\begin{array}{l}\text { Litter (in the streets and public transport system), } \\
\text { dog fouling and pet control, smell / odour pollution }\end{array}$ & 15 \\
\hline Atmospheric issues & $\begin{array}{l}\text { Climate / meteorological information, tropospheric ozone, } \\
\text { pollen / allergens counts, tobacco smoke, UV levels, light pollution }\end{array}$ & 14 \\
\hline Political issues & $\begin{array}{l}\text { Political accountability, citizen influence and action, } \\
\text { national and European policy, environmental reports from governmental } \\
\text { authorities, strategic planning / shaping the greater London authority }\end{array}$ & 13 \\
\hline $\begin{array}{l}\text { "Big" environmental } \\
\text { issues }\end{array}$ & $\begin{array}{l}\text { Global issues, climate change / global warming, globalisation } \\
\text { sustainable development, sustainable economic development, } \\
\text { Third World debt }\end{array}$ & 12 \\
\hline Waste & $\begin{array}{l}\text { Environmental discharge, toxic waste and transportation of it, } \\
\text { nuclear waste transportation and handling, sea pollution by waste delivered } \\
\text { from London, oil and other residuals from private car washing }\end{array}$ & 10 \\
\hline $\begin{array}{l}\text { Business related } \\
\text { issues }\end{array}$ & $\begin{array}{l}\text { Corporate pollution (including nuclear), environmental accountability of } \\
\text { businesses, sustainable business practice }\end{array}$ & 10 \\
\hline Water issues & $\begin{array}{l}\text { The Thames and London's waterways and rivers, aquatic life system, water } \\
\text { conservation }\end{array}$ & 9 \\
\hline Energy & $\begin{array}{l}\text { Electricity and its impact on the environment, energy consumption and } \\
\text { energy from alternative sources }\end{array}$ & 7 \\
\hline Health issues & $\begin{array}{l}\text { Environmental health statistics and epidemiological information, } \\
\text { lead poisoning, tobacco smoke }\end{array}$ & 5 \\
\hline Other issues & $\begin{array}{l}\text { Light pollution, natural hazards, human ecology, comparison with other } \\
\text { cities, coverage of environmental issues in the media, art and culture, } \\
\text { environmental education, ecological vandalism, } \\
\text { anti social behaviour of neighbours, employment / volunteering } \\
\text { opportunities }\end{array}$ & 11 \\
\hline
\end{tabular}

Table 2 - Issues that are missing from the questionnaire 


\section{Presentation and sources of environmental information}

The second part of the questionnaire started with two sets of opinion questions. The first set focused on the content and presentation of the information. The selection of content and interfaces showed a trend towards preference of processed information - text, illustration and map were favoured by about $78 \%$ compared with about $34 \%$ who required access to the raw data (while $50 \%$ thought that such access is useful in some cases). Interest in online data processing and manipulation was even lower (less then 30\%). Respondents were interested in contacting environmental organisations (68\%), gaining access to local environmental information (60\%), and finding information about environmental health issues (58\%) but less interested in contacting an expert (33\%) or engaging in an on-line discussion (25\%). Only $21 \%$ respondents expressed interest in personalised and customised information systems.

\begin{tabular}{llc}
\hline Rank & Source & Percentage \\
\hline & Never seek & $17.9 \%$ \\
& & \\
1 & National newspaper & $61.3 \%$ \\
2 & TV / Radio & $48.7 \%$ \\
3 & Local newspaper & $48.1 \%$ \\
4 & Internet & $43.4 \%$ \\
5 & Environmental organisations & $34.6 \%$ \\
6 & Magazines & $25.8 \%$ \\
7 & Governmental reports & $18.5 \%$ \\
8 & Environmental professionals & $15.8 \%$ \\
9 & Regulatory bodies & $12.9 \%$ \\
10 & Legislation & $9.7 \%$ \\
11 & CD ROM & $2.9 \%$ \\
& & \\
& & $n=341$
\end{tabular}

Table 3 - Sources of information (multiple-choice selection, percentage is calculated for $n$ )

Table 3 presents the sources of information that the respondents currently use to retrieve environmental information. The question stated "do you ever seek information" and respondents perceived it as the active pursuit of information. $17.9 \%$ stated that they do not seek environmental information ${ }^{4}$. Among those who do actively seek information, there are a number of common combinations. The top ten combinations are presented in Table 4 . They account for approximately $37 \%$ of those who seek information. Both tables show that the main sources of information are still "old media" and the role of computerised sources is limited.

\footnotetext{
${ }^{4}$ Bickerstaff \& Walker (1999) report similar behaviour with respect to air-quality information.
} 


\begin{tabular}{|c|c|c|c|c|c|c|}
\hline 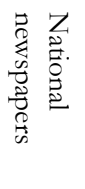 & 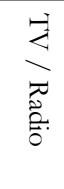 & 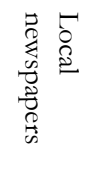 & 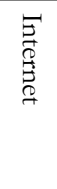 & 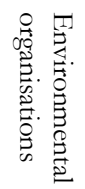 & 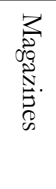 & 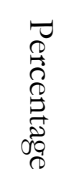 \\
\hline$X$ & $X$ & $X$ & & & & $7.1 \%$ \\
\hline$X$ & $X$ & $x$ & $X$ & $X$ & $X$ & $5.0 \%$ \\
\hline \multirow[t]{2}{*}{$X$} & $X$ & & & & & $3.9 \%$ \\
\hline & & $X$ & & & & $3.6 \%$ \\
\hline$X$ & $X$ & $x$ & & & $X$ & $3.6 \%$ \\
\hline$X$ & $X$ & $x$ & $X$ & & & $3.6 \%$ \\
\hline$X$ & & $x$ & & & & $3.2 \%$ \\
\hline \multirow[t]{2}{*}{$x$} & & & & & & $2.5 \%$ \\
\hline & $X$ & $X$ & & & & $2.1 \%$ \\
\hline$X$ & $X$ & & & & & $2.1 \%$ \\
\hline
\end{tabular}

Table 4 - Popular combinations of information sources

Some of those who seek information connect information gathering with an action or activity, such as finding out about air pollution levels before deciding whether to cycle to work or not. However, far more important is the use of information to simply inform. More then half of the respondents claim that they use environmental information to consider possible future actions, to develop political stances and generally "to know what is going on" (as two respondents wrote).

An interesting aspect of this activity is the perceived obstacles that respondents feel stand between them and the information. The information search and gathering process is perceived as costly (direct costs, time and knowledge):

"I have contacted the [local] council to find about recycling facilities in the area, regulations on burning garden waste and cycle routes. They were friendly and willing to help, but it took a lot of time to get the information I wanted..."

\section{Perception of Internet-based environmental information system}

Respondents' answers seemed to relate to general concepts about the Internet and not specifically to environmental information delivery. Respondents view the Internet as an immediate medium which is available anytime and directly from the user's desktop - a well known and one of the most common depictions of the Internet (Kitchin 1998, Dodge and Kitchin 2001, Dutton 1999). It is seen as a medium that holds the promise (or ability) to deliver the exact piece of information required faster and easier then other forms (such as books).

Another concept that is common among respondents is the view that the Internet is capable of providing current information. As the computer screen does not reveal the date of the information, respondents felt 
that system designers should put in the effort to keep the information current and to state explicitly the date of this information. The Internet is also perceived as a tool with the potential to provide more details about topics which other media cannot. The balance between the richness of sources and information overload was noted by some.

On the downside, respondents are aware that Internet access is not equal among all social groups and that:

“... It is very often overlooked that the vast majority of people DO NOT even have access to a computer, let alone the Internet."

The aspect of the Internet as an environment in which the costs of publication are very low, and therefore almost anyone can publish information is seen as a cause of concern. The reader of information obtained from it must be "on guard" and suspicious of it. The respondents view credibility as a major cause of concern and even question the credibility of the LEO Website.

Technical aspects of Internet were also mentioned. The speed of access to information is considered as important, and aspects such as design and other aspects that relate to the technology behind the Website were raised.

\section{Discussion}

\section{What are the information needs?}

The survey has shown that environmental information needs relate mainly to respondents' day-to-day activities, with a mix between livelihood issues, quality of life, and health issues. No doubt, the survey respondents accept the concept of interconnectedness between environmental elements and issues. The connections between public transport, air quality, traffic and noise were mentioned several times. Traffic in all its forms is a major issue that comes up repeatedly throughout the survey. The necessity to move around London for work, shopping, or leisure is seen as unavoidable. Transportation is the most important issue that emerges from the whole survey.

Air quality, water quality, health risks and noise are all connected to one's personal fitness and of vital importance to the individual respondent's family. Notably, apart for some reference to society as a whole ("it's important to us all") the main focus is on the individualistic level. Despite the environmental rhetoric on future generations and care for all species, they are not expressed as a major issue of interest or concern.

Recycling is expressed as a basic and easy method to "do something" and improve the state of the environment. This is of special interest when compared with the disinterest in active political action such as involvement in campaigns. Such preferences for personal action were recorded by others, too 
(Witherspoon, 1994) although when examined closely, there are gaps between stated behaviour and practical action (Harrison et al. 1996).

Although most of the respondents $(65 \%)$ were satisfied with the list of the environmental topics in the survey, a look at Table 2 will reveal some interesting points. The survey stated clearly that it focuses on an environmental information system for London (i.e. a highly urbanised location). This statement did not prevented few respondents from mentioning and connecting their answers to broader environmental issues and problems, some of them at the global scale. Despite the impression that this list produces, it is important to stress that the local level is the most important to the respondents. Some mentioned the specific locality in which they live or work. The respondent's identity as a person who lives and works in London has an important role in their interest in environmental information.

Finally, though the respondents clearly know how to manipulate and navigate through a Website, they prefer to receive processed information. They would like to receive information about environmental organisations, to learn about local issues and health related topics and to view the information in an attractive visual form. The reasons for this can be explained in the light of current patterns of information sources.

\section{What are the current sources of environmental information?}

One of the most interesting outcomes of the survey is the relationship between old and new media sources. As was noted, most of the respondents exhibit high levels of Internet literacy. There is an abundance of environmental information on the Internet ${ }^{5}$ - from raw data which is broadcast directly from monitoring stations, to politically charged statements by specific interest groups. In spite of this, the percentage of respondents who used the Internet to find environmental information (49\%) is significantly lower than those with frequent access to it $(69 \%)$ !

On the other hand, "traditional media" - TV, radio and newspapers - are the most important and commonly used sources of information. National newspapers are, by far, the commonest source of information. Taking into account the landscape of national newspapers in the UK and their tendency to cover environmental issues (Neale 1999, Chapman et al. 1997, Anderson 1997) it can be concluded that it is mainly the broadsheet newspapers (such as "The Guardian" or "The Times") which are used as the source. The lesser importance of radio and TV can be attributed to their lack of coverage of environmental issues, as one of the respondents mentioned. These findings are similar to the Europeanwide findings (Centre d'Estudis d'Informacio Ambiental 1998) and similar UK studies (Bickerstaff and Walker 1999). As for other sources of information, it is noteworthy that the percentage of respondents that receive information from NGOs is higher then those who declare that they are active in such

${ }^{5}$ For a focused analysis on the relationship between Websites and the use of the Internet for environmental debate see Rogers (1998). 
organisations. Hence, we must conclude that they have received information from these NGOs through a secondary source (be it post, brochure or other means).

There is a relatively limited use of official sources of information (governmental reports etc.). Possible reasons for this can be distrust of such bodies, which have been recorded and documented (Eden 1996, Neale 1999) or simply due to difficulties in accessing and obtaining information from them.

Finally, an important aspect of information sources is that in most cases multiple sources were used. Newspapers (local and national) are the only sources that are use in solitude. The other sources are used to support or to enhance the picture about the issue in question. The distrust of the Internet as a reliable source of information reduces the likelihood of using it as the sole source.

\section{Why is environmental information needed?}

When examining the analysis of sources of information and advantages and disadvantages of the Internet, a very interesting picture emerges. Usually, information and information systems are seen in conjunction with an activity - usually an immediate one (Alter 1996). This aspect of environmental information consumption can be identified in the survey. Respondents stated that they need information about traffic and public transport to plan their daily journeys, or air pollution levels to make a decision on the use of preventive medication. The best connection between information and action is exhibited in recycling. Respondents have clearly indicated that they want to obtain information about recycling in their area as this environmental issue can be tackled through a personal action. However, the answers about sources of information and the textual answers reveal another aspect. This side of consumption is connected with the need "to know what's going on". This is a service that broad spectrum media (TV, radio and general newspapers) have focused on for a long time (see Anderson (1997) and Chapman et al. (1997) for a detailed discussion). An information system, on the other hand, is viewed as a "narrow band" vehicle, which although capable of providing detailed information about a specific topic, cannot compete with traditional media on the general provision of news. In a way, it is possible to envisage the role of PEIS as an in-depth extension of general media.

\section{Using the Internet as a delivery medium}

When the Internet is considered as a delivery medium, it is noteworthy that about $25 \%$ of the respondents who answered the question on the advantages and disadvantages of Internet-based PEIS, felt that the lack of equality is an important element. At least in this sense, the approach that Agenda 21 promoted is endorsed by significant share of the respondents

It is also fascinating to observe that respondents see the issues that relate to the "how" (the technical aspects of Internet-based system) with the "what" (content and presentation). The respondents recommended that the information be presented in a simple and jargon-free manner, but connected this aspect to the way in which the information is laid out on the screen. By and large, the respondents 
preferences follow findings of many Web usability studies (see Nielsen 1999, Rosenfeld and Morville 1998). This aspect holds an important lesson for the designers of Internet-based PEIS: the "user experience" with the Website, as far as common elements are concerned (navigation, search, look and feel), should follow established designs and conventions.

\section{Conclusions}

The London Environment Online survey revealed some of the core concepts and the needs of a significant user group of PEIS. At least on the basis of their profile, they are the would-be users of existing Internet-based systems. Therefore, the most intriguing finding is the (relative) limited use of existing computerised resources. At least for this aspect, the inherent bias in the recruitment is reemphasising the probable failure of existing systems. After all, the Internet-based systems of "environmental information providers" such as the Environment Agency or Friends of the Earth were constructed to provide information, and their limited use by the survey's respondents is somewhat alarming. Put simply, if the highly-educated/highly-connected cannot find the information that they want, how can we expect ICT to fulfil their role in increasing environmental awareness? Bullard (2000) has found that at the local level (which is the most important for many users) local authorities have not managed to use their Websites to promote Local Agenda 21 issues. This type of information is relatively static and only undergoes slow changes. Therefore, the more timely and quicker changing information that the survey respondents seek is posing an even grater challenge for information providers at all levels.

Secondly, the user group is not a monolithic body, and even at the individual level there is no single identity or affiliation that will give an unequivocal definition of their needs and requirements from such a system. As noted elsewhere (Haklay Forthcoming) PEIS designers and maintainers should respond to this by providing flexible information systems without attempting to provide "one size fits all" solutions. Such systems should target different user groups and provide useful and easily accessible information. This can be done through the process of personalisation and customisation of the information system (but is must be noted that only fifth of the respondents expressed interest in such functionality), or re-thinking the delivery and communication in such ways which are effective for important channels such as the media, NGOs, local activity groups or other information intermediaries.

As we move to an era when more and more information is available, sometimes exclusively, through Web-based systems, there will be a need to consider and accommodate many other user groups. These include users with limited ICT knowledge, occasional users or user with wide range of socio-economic and cultural backgrounds. Only when these groups are considered thoroughly, the outreach element (increased awareness) can be achieved. Another aspect that deserves attention is to gain a better understanding of local informal networks, and to improve information provision to support information intermediaries. 
Another aspect of the survey is its context - a highly developed country and an urban environment. As Chapman et al. (1997) noted, this aspect creates a specific cultural context. The needs of rural users, for example, might be different from those in London. Further afield, there is a need to evaluate the usefulness of existing systems and to understand the communicative and interactive role of operating PEIS (such as governmental or NGO Websites).

The development of Web-based PEIS must relate to the emerging literature on various social aspects of Internet use (such as Kitchin 1998, Dutton 1999, Rheingold 1993, Turkle 1995), and more specifically to those who deal with its used to environmental communication (O'Lear 1997, Perry and Leigh Vandeklein 1996, Pickerill 2000, Rogers 1998, Bullard 2000). The survey reported here is intended to contribute to this literature and can be seen as a starting point for a more user-centred approach to PEIS, where the needs from the system are driven by user requirements and needs.

\section{Acknowledges}

The pilot phase of the study was carried out by UCL's Human Computer Interaction (HCI) students, under the guidance of Dr. A.Sasse and S. Brostoff. The qualitative analysis was assisted by UCL's Public Understanding of Environmental Change students (especially C.Ohm Andersen, S.Herrerra, A.Garfunkel and T.Bowden) under the guidance Dr. G.Davis and Prof. C.Harrison. Special thanks to D.Lloyd. 


\section{References}

Alter, S. (1996) Information Systems : A Management Perspective (Benjamin/Cummings Pub. Co., Menlo Park, CA).

Anderson, A. (1997) Media, Culture and the Environment (U.C.L. Press, London)

Bickerstaff, K. and Walker, G. (1999) 'Clearing the Smog? Public Responses to Air-Quality Information' Local Environment, 4, 279-294.

Bowman, J. (2000) 'Internet Access - 1st Quarter 2000', National Statistics, London, pp. 5.

Bristow, T. K. (1996) 'Aspects of Environmental Awareness in England and Wales: Case Studies', PhD thesis, University of London (RHBNC), London, pp. 400.

Bullard, J. E. (2000) 'Sustaining Technologies? Agenda 21 and Uk Local Authorities' Use of the World Wide Web’ Local Environment, 5, 329-341.

Burgess, J., Harrison, C. M. and Limb, M. (1988) 'People, Parks and the Urban Green: A Study of Popular Meanings and Values for Open Spaces in the City' Urban Studies, 25, 455-473.

Castells, M. (1996) The Rise of the Network Society (Blackwell Publishers, Malden, MA).

Centre d'Estudis d'Informacio Ambiental (1998) 'A New Model of Environmental Communication for Europe - from Consumption to Use of Information', Centre d'Estudis d'Informacio Ambiental, Barcelona, Spain, pp. 65.

Chapman, G., Kumar, K., Fraser, C. and Gaber, I. (1997) Environmentalism and the Mass Media: The NorthSouth Divide, Routledge, London .

CommerceNet/Nielsen Media Research (1999) 'E-commerce Survey Shows 27\% of British Adults Now Use the Internet on a Regular Basis'

(http://www.q4.com/cnet.objects/Templates/pr/pr271099.html) Accessed 19 December 1999

CommerceNet/Nielsen Media Research (2001) Internet usage for the month of July 1002 (http:/ / epm.netratings.com/uk/web/NRpublicreports.usagemonthly) Accessed 12 August 2001.

Diekmann, A. and Franzen, A. (1999) 'The Wealth of Nations and Environmental Concern' Environment and Behavior, 31, 540-549.

Dodge, M. and Kitchin, R. (2001) Mapping Cyberspace, Routledge, New York.

Dunlap, R. E., Van Liere, K. D., Mertig, A. G. and Jones, R. E. (2000) 'Measuring Endorsement of the New Ecological Paradigm: A Revised NEP Scale' Journal of Social Issues, 56, 425-442.

Dutton, W. H. (Ed.) (1999) Society on the Line: Information Politics in the Digital Age, Oxford University Press, New York.

Eden, s. (1996) 'Public Participation in Environmental Policy: Considering Scientific, Counter-Scientific and Non-Scientific Contributions' Public Understanding of Science, 5, 183-204.

Foley, P. (2000) 'Whose Net? Characteristics of Internet Users in the UK Graduate Business School', De Monfort University, Leicester, pp. 14.

Haklay, M. (2000) 'London Environment Online -User Requirement Study - Final Report' Centre for Advanced Spatial Analysis, UCL, London, pp. 40.

Haklay, M. (Forthcoming) 'Public Access to Environmental Information: Past, Present and Future' Computers, Environment and Urban Systems.

Hallo, R. E. (1997) 'Public Access to Environmental Information', European Environmental Agency, pp. 41. 
Harrison, C. M., Burgess, J. and Filius, P. (1996) 'Rationalizing Environmental Responsibilities. A

Comparison of Lay Publics in the UK and the Netherlands' Global Environmental Change, 6, 215234.

Hawthorne, M. and Alabaster, T. (1999) 'Citizen 2000: Development of a Model of Environmental Citizenship' Global Environmental Change, 9, 25-43.

Inglehart, R. (1977) The Silent Revolution: Changing Values and Political Styles among Western Publics (Princeton University Press, Princeton, N.J.)

Irwin, A. (1995) Citizen Science: A Study of People, Expertise and Sustainable Development, Routledge, London.

Kitchin, R. (1998) Cyberspace : The World in the Wires, John Wiley \& Sons, Chichester .

Neale, G. (1999) Untitled presentation, presented at 'The Public and the Environment: Citizens, Sustainability and Science’ seminar, Royal Geographical Society, London, 14 Apr 1999.

Nielsen, J. (1999) Designing Web Usability: The Practice of Simplicity (New Riders Publishing, New York).

OECD (2000) 'OECD Seminar - Public Access to Environmental Information' Organisation for Economic Co-operation and Development, Athens, pp. 246.

O'Lear, S. (1997) 'Electronic Communication and Environmental Policy in Russia and Estonia' The Geographical Review, 87, 275-290.

Perry, j. and Leigh Vandeklein, E. (1996) 'Environmental Problem Solving in an Age of Electronic Communications: Toward an Integrated or Reductionist Model?' In Scientific Uncertainty and Environmental Problem Solving(Ed, Lemons, J.) Blackwell Science, Cambridge, Mass., pp. 345-376.

Pickerill, J. (2000) 'Spreading the Green Word? Using the Internet for Environmental Campaigning' Ecos, 21, 14-24.

Princeton Economic Research Inc. (1998) 'Environmental Data and Information: Interim Findings from the EPA Customer Survey (Phase III Report)’ Washington DC, pp. 112.

Rheingold, H. (1993) The Virtual Community: Homesteading on the Electronic Frontier, Addison-Wesley Pub. Co., Reading, Mass.

Rogers, J. (1998) 'Creating New Political Spaces?: NGOS and Their Use of Network Technologies' paper resented at Colloquium on the Possibilities for Transnational Democracy at Newcastle University 12-13 Dec.

Rosenfeld, L. and Morville, P. (1998) Information Architecture for the World Wide Web (O'Reilly, Sebastopol, CA).

Shiffer, M. J. (1999) 'Managing Public Discourse: towards the augmentation of GIS with Multimedia' In Longley, P., Goodchild Michael, F., Maguire, D. J. and Rhind, D. (eds) Geographical Information Systems (John Wiley \& Sons Inc., New York) 723-732.

Turkle, S. (1995) Life on the Screen: Identity in the Age of the Internet, Simon \& Schuster, New York.

UN (1992a) ‘Agenda 21 United Nations', Rio de Janeiro.

UN (1992b) 'The Rio Declaration on Environment and Development' United Nations, Rio de Janeiro.

UN/ECE (1998) 'Convention on Access to Information, Public Participation in Decision-Making and Access to Justice in Environmental Matters’ ECE Committee on Environmental Policy, Aarhus, pp. 28.

US Congress (1970) National Environmental Policy Act, pp. P.L. 91-190, S. 1075.

USDOC/NTIA (1999) 'Falling through the Net : Defining the Digital Divide' NTIA, Washington D.C.

Witherspoon, S. (1994) 'The Greening of Britain: Romance and Rationality' In Jowell, R., Curtice, J., Brook, L., Ahrendt, D. and Park, A. (eds) British Social Attitudes - the 11th Report (Social and Community Planning Research, Cambridge) 107-139. 
Witherspoon, S. and Martin, J. (1992) ‘What Do We Mean By Green?’ In Jowell, R., Brook, L., Prior, G. and Taylor, B. (eds) British Social Attitudes - the 9th Report (Social and Community Planning Research, Cambridge) 1-26. 